\title{
Clinical significance of Saussurea Costus in thyroid treatment
}

\author{
Muhammad Mujammami, MBBS, MS.c.
}

\begin{abstract}
ينتمي نبات القسط أو القسط الهندي إلى عائلة Asteraceae وهو أحسد

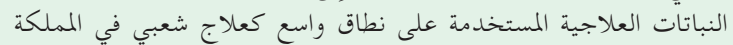

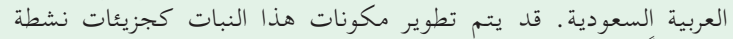

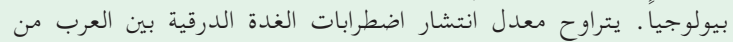

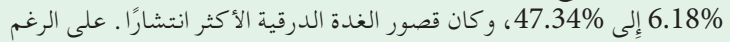

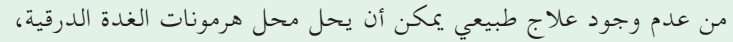

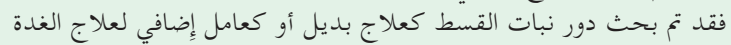

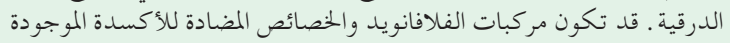

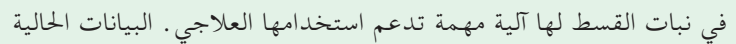

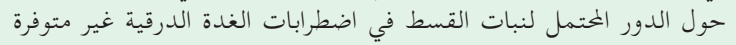

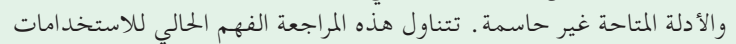

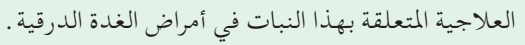

Saussurea costus (S. costus) belongs to family of Asteraceae and is one of the therapeutic plants extensively used as a traditional medicine in Saudi Arabia. Constituents of this plant have the potential to be developed as bioactive molecules. Among Arabs, the prevalence of thyroid disorders ranges from 6.18 $\%$ to $47.34 \%$ and hypothyroidism has been reported to be the most prevalent. Although there is no natural treatment that can directly replace thyroid hormones, their role as an alternate treatment or as an add-on to available thyroid treatment has been explored. Flavanoids and antioxidant properties of $S$. costus may be an important mechanism involved in supporting its medicinal use. Current data on the possible role of $S$. costus in thyroid disorders is lacking and the available evidence is inconclusive. This review deal with the current understanding of use and myth regarding the use of this medicinal plant in thyroid disease.

Keywords: thyroid, saussurea, treatment, clinical

Saudi Med J 2020; Vol. 41 (10): 1047-1053 doi: 10.15537/smj.2020.10.25416

From the Endocrinology and Diabetes Unit, Department of Medicine, College of Medicine, King Saud University, Riyadh, Kingdom of Saudi Arabia.
Addresscorrespondenceandreprintrequestto:Dr.MuhammadMujammami, Endocrinology and Diabetes Unit, Department of Medicine, College of Medicine, King Saud University, Riyadh, Kingdom of Saudi Arabia. E-mail:mhmujammami@ksu.edu.sa

ORCID ID: https://orcid.org/0000-0001-5224-0258

Caussurea costus (S. costus) synonymous with Saussurea lappa, also known as (نبات القسط أو القسط الهندي) qust in Arabic or Costus root in English, belongs to family of Asteraceae, a species of thistle in the genus Saussurea found worldwide mostly in Western Himalayan region of Pakistan and India. The growth of S. costus is limited to specific moist Himalayan region at altitude of $2600-4000 \mathrm{~m}^{1}{ }^{1}$ The cultivation of $S$. costus for commercial purpose started in 1920 s. $^{2}$ Since ancient times, oils extracted from the root have been used in traditional medicines and perfumes. ${ }^{3}$ Saussurea costus is one of the therapeutic plants extensively used as a traditional medicine in Saudi Arabia. ${ }^{4}$

The medicinal properties of $S$. costus are well recognized in traditional systems of medicine including, Ayurvedic, Chinese, and Tibetan. The roots of S. costus are bitter in taste with strong aromatic odor and are believed to have anti-inflammatory, antimicrobial, analgesic, anti-ulcer, anticancer, and hepatoprotective properties in humans. Major constituents of this plant have potential to be developed as bioactive molecules. The costus oil (the oil extracted from the roots of S. costus) has been used in leprosy. ${ }^{5}$ Saussurea costus roots have also been used in many other medical conditions including chronic gastritis, stomach ulcers, rheumatoid arthritis, asthma and bronchitis in traditional medicine and in inflammation-related diseases. Saussurea costus is one of the most commercially used herbs in various indigenous systems of medicine. ${ }^{6}$ Data on possible role of $S$. costus in thyroid disorders are lacking. In this article, based on current available evidence, we summarize comprehensive analysis of the role of $S$. costus in thyroid disorders. 
Basic details and therapeutic role of $S$. costus. General pharmacology. Saussurea costus is a medicinally important plant and rich in bioactive phytoconstituents. Until now, many compounds of $S$. costus have been identified including Sesquiterpene terpenes (ST), anthraquinones, alkaloids and flavanoids. Sesquiterpene terpenes are main compounds of $S$. costus root which include dehydrocostus lactone (DCL) (46.8\%), costunolide (CS) (9.3\%), 8-cedren-13-ol (5.1\%) and $\alpha$-curcumene (4.3\%). ${ }^{7,8}$ These constituents have been reported to have medicinal properties and possesses various bioactivities such as antifungal, ${ }^{9}$ antidiabetic, ${ }^{10}$ antihelmintic, ${ }^{11}$ antitumor, ${ }^{12}$ antiulcer, ${ }^{13}$ immunomodulator, ${ }^{14,15}$ anti-inflammatory, ${ }^{14}$ and antihepatotoxic. ${ }^{14}$ Identified flavanoids of $S$. costus possess antimicrobial properties. ${ }^{14}$

Therapeutic role of $S$. costus in various conditions. Antitumor effect. Lee et $\mathrm{al}^{16}$ studied the effect and mechanism of apoptosis in HL-60 human leukemia cells and showed that Costunolide (CS), induces the reactive oxygen species (ROS)-mediated mitochondrial permeability transition and resultant cytochrome $\mathrm{c}$ release. This was a very important report on on the mechanism of the anticancer effect of costunolide. Dehydrocostus lactone isolated from the hexane extract induced apoptosis in cell lines of DU145 human autonomous androgen prostate cancer and induced cell apoptosis. ${ }^{14}$ Ethanolic extract of S. costus showed apoptotic effect in a dose and time dependent manner in the treatment of gastric cancer. ${ }^{12}$

Anti-inflammatory effect. Ethanolic extract of $S$. costus showed anti-inflammatory activities through carrageenan induced paw edema and peritonitis animal models. ${ }^{17}$ Costunolide also showed anti-inflammatory activity by impeding the protein and mRNA expression of interleukin-1b masking the AP-1 transcription activity. ${ }^{18}$

Anti-ulcer effect. The acetone extract from S. costus and CS, exhibited both cholagogic effect and inhibitory effect on the formation of gastric ulcer (induced by restraint in water) in mice. ${ }^{19}$ In ethanol-induced lesion in rats, amino acid-sesquiterpene adducts, saussureamines A, B and C, isolated from the root of $S$. costus showed anti-ulcer effect. Costunolide and DCL also showed

Disclosure. Authors have no conflict of interests, and the work was not supported or funded by any drug company. a gastro protective effect on acidified ethanol-induced gastric mucosal lesions in rats. ${ }^{20}$

Immunomodulatory effect. Costunolide inhibited the killing activity of cytotoxic $\mathrm{T}$ lymphocytes (CTL) through preventing the increasing tyrosine phosphorylation in response to the cross slinking of T-cell receptors. Dehydrocostus lactone along with other guaianolides also exhibited inhibitory activity towards the killing function of CTL and the induction of induction of intercellular adhesion molecule-1 (ICAM-1). ${ }^{20}$ Additionally, extracts of $S$. costus showed hypolipidemic effect when orally administered to rabbits. Saussurea costus was found most effective for obese diabetes when a detailed survey and clinical study on potent hypoglycemic plants of different regions from India. ${ }^{10,20}$

Thyroid disorders and natural treatments. Worldwide, incidence of endocrine diseases including thyroid disorders is increasing. Thyroid disorders are generally classified into hyper and hypothyroidism. Women are more likely to have alteration in thyroid function as compared to men. ${ }^{21}$ In general, patients with thyroid disorders may have decreased circulating thyroid hormones (hypothyroidism) or increased levels of thyroid hormones (hyperthyroidism). Hypothyroidism is one of the most prevalent endocrine disorders characterized by low levels of thyroid hormones (T3 \& T4) in the serum and high thyroid stimulating hormone (TSH). The common cause of hypothyroidism is autoimmune thyroiditis. ${ }^{22}$ The prevalence of hypothyroidism in the general population is variable ranging from $0.3 \%$ to $3.7 \%$ in the United States to $0.2 \%$ to $5.3 \%$ in European population. ${ }^{23-25}$ Approximately, 3\% to $8 \%$ of world population have subclinical hypothyroidism, a condition with no apparent symptoms of thyroid hormone deficiency. The prevalence of overt hyperthyroidism is approximately $0.5 \%$ in both European and American population. ${ }^{24,25}$ In the Arab world, the prevalence of thyroid disorders ranges from $6.18 \%$ to $47.34 \%$. The prevalence of goitre in Arabian countries has been reported to be $25 \%$ in Egypt and $1.7 \%$ in Bahrain. ${ }^{26}$ In comparison to other populations, the prevalence of thyroid dysfunction among Saudi adults has been reported to be higher. Gaffer et $\mathrm{al}^{27}$ reported an overall prevalence of $43.6 \%$ including $40.8 \%$ hypothyroidism and $2.8 \%$ as hyperthyroidism. ${ }^{27}$ Like in other countries, among all thyroid disorders, hypothyroidism has been reported to be the most prevalent among Arab population. Among Arabs, a considerably higher prevalence of hypothyroidism has been documented in Saudi population $(43.3 \%)$ as compared to $6.18 \%$ 
in Libya. ${ }^{28}$ Currently, levothyroxine replacement is the choice of treatment in hypothyroidism. Although, it has been shown that in spite of being euthyroid, patients taking levothyroxine have decreased neurocognitive function and lead a suboptimal quality of life. ${ }^{29}$ Further, levothyroxine treatment is associated with poor compliance. $^{30}$

Natural therapies in thyroid dysfunction. Although, there are no natural treatment that can directly replace thyroid hormones, their role as an alternate treatment or as an add-on to available thyroid treatment has been explored. The results of few available studies provided controversial results suggesting significant role of tea in thyroid cancer. ${ }^{31}$ However, later a pooled analysis showed no such role, although the analysis showed heterogeneity in their results. ${ }^{32}$ Various plants have shown to possess thyrotropic activities (Table 1). All chamomile, sage, and mountain tea have shown association with lower incidence of thyroid diseases both benign and malignant. A study showed that by drinking 2 to 6 cups these teas per week was associated with a reduced incidence of thyroid disease with no clear explanation for this association. Anti-oxidant, antiinflammatory and anti-cancer activity of polyphenols, flavonoids and catechins present in these teas may have a role in protection from thyroid diseases both benign and malignant. Further research is needed to explain these associations. ${ }^{33}$ Ashwagandha, another herb also known Withania somnifera or Indian ginseng, is used in traditional medicines and has shown to normalize thyroid abnormalities in subclinical hypothyroidism in humans after 8 week treatment in a recent small study. ${ }^{34}$ As in hypothyroidism, certain natural treatment has been shown some efficacy in case of hyperthyroidism. In a human study, Lycopus europaeus, commonly called bugleweed has shown to reduce the symptoms of mild hyperthyroidism and autoimmune Graves' disease, which lead to hyperactivity thyroid gland causing hyperthyroidism..$^{35}$ Possibly, lithospermic acid and other organic acids present in bugleweed decrease thyroid hormones (T4). ${ }^{36}$ Bugleweed may inhibits antibodies binding to thyroid gland, a cause of graves disease and may thus help alleviate symptoms of mild hyperthyroidism in Graves disease. ${ }^{37}$ Other natural supplements such as alpha lipoic acid, lemon balm, and motherwort have also been envisaged as therapeutic options. ${ }^{38}$ Cochrane database does not recommend any specific formulation for clinical use. A meta-analysis showed that Chinese herbal medicines have shown therapeutic efficacy for hyperthyroidism when added to standard treatment but due to inclusion of the studies with sub optimal design, the results cannot be inferred as strong evidence. ${ }^{39}$

Use of Yingliu mixture, a preparation of various herbs, mustard seed and oyster when used with antithyroid medication Methimazole showed symptomatic and biochemical improvement in humans with hyperthyroidism/graves disease probably by reducing TSH receptor autoantibodies (TRAb), TNF- $\alpha$ and IL-10, levels and increasing CD4+CD25+. ${ }^{40}$ Role of natural treatment in thyroid tumors has also been explored. An animal study showed that a seaweed plant, Fucus vesiculosus has shown to inhibit thyroid tumor cell growth in laboratory environment; however, human data in this regard are lacking. ${ }^{41}$ Haizao Yuhu Decoction (HYD), a constituent of a Chinese herb, Thallus Sargassi Pallidi and Radix Glycyrrhizae, has shown to reduce size of thyroid gland (Goitre) by regulating thyroid hormone synthesis in animals. ${ }^{42}$ Various natural treatments have been investigated as an alternative treatment of thyroid diseases but more robust evidence is required before any specific kind of natural therapy can be recommended.

Table 1 - Effect and possible mechanism of various plants preparations on thyroid function.

\begin{tabular}{lll}
\hline Plant preparation & Effect on thyroid function & Possible mechanism \\
\hline Chamomile, Sage and mountain tea & $\begin{array}{l}\text { Lower incidence of benign and malignant } \\
\text { thyroid disease } \\
\text { Ancreased thyroid hormones levels }\end{array}$ & $\begin{array}{l}\text { Anti-oxidant, anti-inflammatory. Role of polyphenols, } \\
\text { flavanoids in anti-cancer effect }\end{array}$ \\
$\begin{array}{l}\text { Solanaceae) } \\
\text { Bugleweed (Lycopus europaeus) }\end{array}$ & Lowers thyroid hormone levels & Anti-oxidant \\
$\begin{array}{l}\text { Yingliu mixture (mixture of various herbs, } \\
\text { mustard seeds and oyster) }\end{array}$ & Helps in reducing thyroid hormone & Inhibition of autoantibody binding receptor activity \\
$\begin{array}{l}\text { Haizao Yuhu Decoction (HYD), Constituent } \\
\text { of Chinese herb }\end{array}$ & Reduce thyroid gland (Goitre) & $\begin{array}{l}\text { TRAb, TNF- } \alpha \text { and IL-10, levels and increasing } \\
\text { CD4 CD25 }\end{array}$ \\
\hline
\end{tabular}


A summary of effects of $S$. costus on thyroid function is shown in Table 2.

Role of $S$. costus in thyroid disorders and other human disease and its side effects. The potential role of $S$. costus has been explored in the treatment of various diseases. In an animal study, $S$. costus root extract decreased sodium and calcium ions and reduced renal toxic effects caused by ethephon (2-chloroethylphosphonic acid), a plant growth promoter used to control the plant growth process. ${ }^{43} \mathrm{~A}$ study by Abd Eldaim et $\mathrm{al}^{44}$ showed protective effect of $S$. costus on ethephon induced reproductive toxicity in rats by ameliorating sperms abnormalities, testicular tissue and DNA damages, P53 protein expressions. Dehydrocostus lactone, a sesquiterpene from $S$. costus, suppresses allergic airway inflammation by binding to dimerized translationally controlled tumor protein, a protein involved in many allergic disorders. ${ }^{45}$ Sesquiterpene lactones from S. costus root extracts and semi synthetic sesquiterpene analogues play a role in tumor necrosis factor, an inflammatory cytokine inhibition. ${ }^{46}$

In-vitro study has shown that in hepatocellular carcinoma, the volatile oil from $S$. costus inhibits the epithelial growth factor receptor thyrosine kinasemediated signalling pathway and exerts its antitumor effect. ${ }^{47}$ In a small human study Upadhyay et $\mathrm{al}^{48}$ showed that Aquous extract of $S$. costus improved clinical and biochemical parameters, coronary circulation and myocardial function in patients suffering from ischemic heart disease.

The role of $S$. costus has been explored in various endocrine diseases. In animal models, the alcoholic extract of the root of $S$. costus improved hypoglycemic response without increase in plasma insulin with initial accumulation of glycogen in the liver followed by its depletion. Its effect on the histology of thyroid gland was shown to be stimulatory, no toxic effect was observed in liver (on doses up to $400 \mathrm{mg} / \mathrm{kg}$ body weight) and no change was observed in adrenal gland and pancreas. ${ }^{49}$

Recently, a study in adult rats evaluated the effect of root extract of $S$. costus on thorium toxicity in brain also assessed the antioxidant effect and modulation activity of thyroid gland. Thorium accumulation caused disturbance in sodium and potassium ions and decrease in monoamines in brain also lead to oxidative stress which was evident by increased lipid peroxidation and decrease glutathione content. Thorium also increased thyroid-stimulating hormone (TSH), triiodothyronine (T3), and thyroxine (T4) levels. These effects of thorium were mitigated with prior oral administration of $S$. costus extract suggesting its protective effect mainly through its antioxidant mechanism. ${ }^{45}$ Antioxidant properties of various plant extracts may be an important mechanism involved in potentiating their medicinal use in various ailments. ${ }^{46}$

Renal, hepatic and lipid abnormalities are seen in thyroid dysfunction..$^{50,51}$ Ethanoic extract of $S$. costus has shown hepatoprotective effect in rats, poisoned with carbon tetrachloride. Liver plays an important role in regulating metabolism of thyroid hormones and similarly thyroid hormones regulate liver function. A study showed that as compared to non-treated mice, treatment with $S$. costus root extract alleviated hyperthyroidism and hypothyroid induced hepatic enzymes derangements. The same study also revealed ameliorating effects of Costus extract on altered TSH, T4, sodium, potassium, chloride, albumin, creatinine, urea, calcium ions, cholesterol and triglycerides levels

Table 2 - Summary of effects of Saussurea costus (S. costus) on thyroid function.

\begin{tabular}{|c|c|}
\hline Authors/references & Effect of $S$. costus on thyroid function \\
\hline Ansari et $\mathrm{al}^{2} 2019$ & Alleviation of hyper/hypothyroidism induced hepatic enzyme derangements \\
\hline Bolkiny et al ${ }^{52} 2019$ & $\begin{array}{l}\text { Ameliorating effects on altered thyroid stimulating hormone, thyroxine, sodium, potassium, chloride, albumin, creatinine, } \\
\text { urea, calcium ions, cholesterol and triglycerides levels in hypo and hyperthyroidism. }\end{array}$ \\
\hline Bolkiny et al ${ }^{52} 2019$ & $\begin{array}{l}\text { Normalized of lipid abnormalities by reducing plasma low-density lipoproteins (LDL) cholesterol, possibly through increased } \\
\text { LDL receptor activity }\end{array}$ \\
\hline Ahmed et $\mathrm{al}^{54} 2018$ & $\begin{array}{l}\text { Amelioration of most signalling pathways and in different tissues in hyperthyroidism through flavanoids reducing thyroid } \\
\text { peroxidise activity (may be pronounced during iodine deficiency) }\end{array}$ \\
\hline Ahmed et $\mathrm{al}^{54} 2018$ & Chelating effect through bonding with inorganic iodide in amelioration of hyperthyroidism \\
\hline Alnahadi et $\mathrm{al}^{4} 2017$ & $\begin{array}{l}\text { Alleviation of pesticide induced toxic effects on thyroid gland function by improving histomorphological changes in thyroid } \\
\text { gland }\end{array}$ \\
\hline Alnahadi et $\mathrm{al}^{4} 2017$ & Hypolipidemic effect in hypothyroidism induced hyperlipidemia and favourable modulating impact on the thyroid hormones \\
\hline
\end{tabular}


in hypo and hyperthyroid mice. ${ }^{52}$ Thyroid hormones may affect renal, electrolytes and mineral metabolism; however, the exact mechanism for these changes is not clear. Some authors have reported altered levels of electrolytes in hypo and hyperthyroidism whereas some contradicts this observation. ${ }^{53}$ Possibly due to altered metabolic clearance, cholesterol, low density lipoprotein (LDL) levels are increased in hypothyroidism. In a mice study, oral $S$. costus treatment normalized these lipid abnormalities by reducing plasma LDL cholesterol, possibly through increased LDL receptor activity. ${ }^{52} \mathrm{~A}$ study from Egypt by Sahar et $\mathrm{al}^{54}$ showed that a polyherb with S. costus "as one of its constituents at low doses" was effective in treating LT4 induced hyperthyroidism in rats and found it to be safer than anti thyroid drug Carbimazole and ameliorated most signalling pathways and in different tissues. These favorable effects of polyherb on thyroid gland may have been induced by flavonoids such as dillapiole, costunolide and caffeic acid by reducing thyroid peroxidase activity. These effects may be pronounced when iodine is deficient. Other flavonoids, such as kaempferol and quercetin, have also shown irreversible inhibitory effect on thyroid peroxidise activity. Additionally, Tannins like gallic acid and epigallocatechin gallate, which exhibit chelating effect through bonding with inorganic iodide might play a role in ameliorating hyperthyroidism..$^{54}$ Another animal study by Han et $\mathrm{al}^{55}$ in Saudi Arabia assessed the protective effect of aqueous extract of $S$. costus and showed alleviating toxic effects of pesticide on thyroid gland function. Prior treatment by $S$. costus extract in pesticide intoxicated rats improved histomorphological changes in thyroid gland and up modulated thyroid hormones suggesting its protective effect against adverse impact of deltamethrin, a pesticide. This may be related to antioxidant activity of $S$. costus. As hypothyroidism may induce hyperlipidemia, the same study also revealed hypolipidemic effect of the extract of $S$. costus which may be linked to its favorable modulating impact on the thyroid hormones. ${ }^{4}$ Based on such observations, it was proposed that $S$. costus roots can be used as an adjuvant co-therapy to propylthiouracil and thyroxine treatment in hypo- and hyperthyroidism respectively. ${ }^{52}$ A schematic diagram of various biological effects of S. costus is shown in Figure 1.

Safety and side effects of $S$. costus. Not much information is available about safety and side effect profile of S. costus. Generally, S. costus root may be safe when taken appropriately by mouth but $S$. costus may contain a contaminant called aristolochic acid which may have nephrotoxic and carcinogenic effects. ${ }^{55}$ Safety of $S$. costus has not been ascertained in pregnant or breast-feeding women. Saussurea costus may cause an

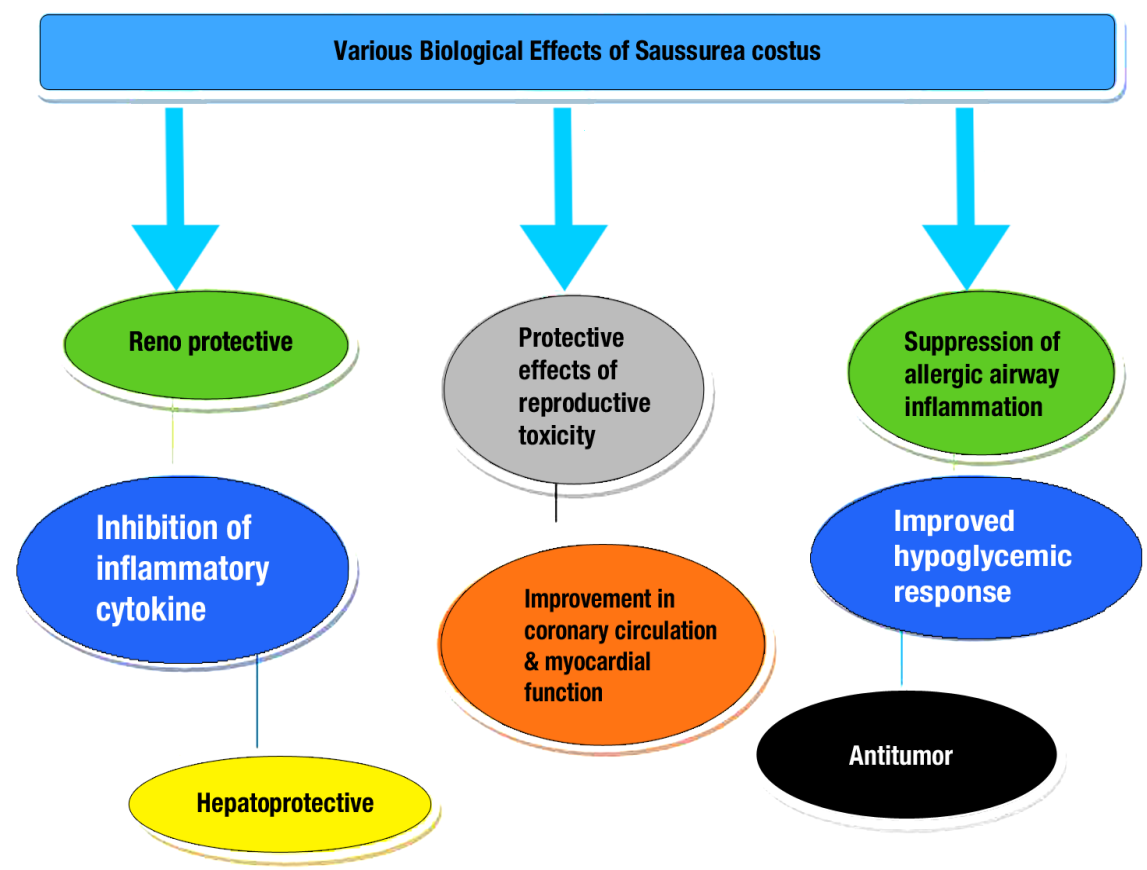

Figure 1 - Schematic diagram of various biological effects of Saussurea costus. 
allergic reaction in those who are allergic to Saussurea species, their constituents including the sesquiterpene lactones (STL). Those exposed to STLs, have been observed to develop contact dermatitis. Concerns have been raised about their concerns regarding the genotoxic embryotoxic potential of these compounds. In vivo and vitro assays have reported mutagenic effect of STLs. ${ }^{56}$

In conclusion, natural therapies are not usually considered a part of standard care modern medicine which is evidence based. It has been envisaged to use natural therapies as a co treatment along with standard treatment speculating absence of side effects of natural treatments and in quest to do more to alleviate ones symptoms and improve health. Available data has shown some role of $S$. costus in the management thyroid disorders in animal models but has not been proven for clinical use. The current available evidence is inconclusive regarding thyrotropic activities of $S$. costus and its potential role in the management of thyroid disorders in humans. More research is needed quantify the effectiveness of $S$. costus for its use in thyroid disorders.

\section{References}

1. Shah R. Nature's Medicinal Plants of Uttaranchal: (Herbs, Grasses and Ferns). Gyanodaya Prakashan (IN): Scientific Research; 2004.

2. Ansari S. Ethnobotany and Pharmacognosy of Qust/Kut (Saussurea lappa, CB Clarke) with Special Reference of Unani Medicine. Pharmacogn Rev 2019; 13: 71-76.

3. Negi VS, Kewlani P, Pathak R, Bhatt D, Bhatt ID, Rawal RS, et al. Criteria and indicators for promoting cultivation and conservation of Medicinal and Aromatic Plants in Western Himalaya, India. Ecol Indic 2018; 93: 434-446.

4. Alnahdi HS. Injury in metabolic gland induced by pyrethroid insecticide could be reduced by aqueous extract of Sassura lappa. International Journal of Pharmaceutical Research \& Allied Sciences 2017; 6: 97-86.

5. Al-Adhroey AH, Al-Abhar YM, Noman NM, Al-Mekhlafi HM. Ethnopharmacological survey of herbal remedies used for treating malaria in Yemen. J Herb Med 2020; 21: 100332.

6. Chen SL, Yu H, Luo HM, Wu Q, Li CF, Steinmetz A. Conservation and sustainable use of medicinal plants: problems, progress, and prospects. Chin Med 2016; 11: 37.

7. Ebadi N, Bagheri S, Manayi A, Toliyat T, Sadrai S, Tabarrai $M$, et al. Determination of scientific name of bitter "Qust": an important controversial plant source in the Iranian medicinal plants market for neurological complications. Research Journal of Pharmacognosy 2018; 5: 25-32.

8. Hassan R, Masoodi MH. Saussurea lappa: A comprehensive review on its pharmacological activity and phytochemistry. Curr Tradit Med 2020; 6: 13-23.

9. de Andrade EF, Carpiné D, Dagostin JL, Barison A, Rüdiger AL, de Muñiz GI, et al. Identification and antimicrobial activity of the sesquiterpene lactone mixture extracted from Smallanthus sonchifolius dried leaves. Eur Food Res Technol 2017; 243: 2155-2161.
10. Amara U, Khan A, Laraib S, Wali R, Sarwar U, Ain QT, et al. Conservation status and therapeutic potential of Saussurea lappa: an overview. Am J Plant Sci 2017; 8: 602-614.

11. Kadhem M. Protective of ethanolic extract of Saussurea lappa against paracetamol-induced hepatic and renal damage in male rabbits. Asian J Pharm Clin Res 2019; 12: 68-73.

12. Sheikh BY, Sarker MM, Kamarudin MN, Ismail A. Prophetic medicine as potential functional food elements in the intervention of cancer: A review. Biomed Pharmacother 2017; 95: 614-648.

13. El-Rahman GI, Behairy A, Elseddawy NM, Batiha GE, Hozzein WN, Khodeer DM, et al. Saussurea lappa ethanolic extract attenuates triamcinolone acetonide-induced pulmonary and splenic tissue damage in rats via modulation of oxidative stress, inflammation, and apoptosis. Antioxidants 2020; 9: 396.

14. Zahara K, Tabassum S, Sabir S, Arshad M, Qureshi R, Amjad MS, et al. A review of therapeutic potential of Saussurea lappa-An endangered plant from Himalaya. Asian Pacific Journal of Tropical Medicine 2014; 7: S60-S69.

15. Abdallah EM, Qureshi KA, Ali AMH, Elhassan GO. Evaluation of some biological properties of Saussurea costus crude root extract. Biosci Biotech Res Comm 2017; 10: 601-611.

16. Singireesu SS, Misra S, Mondal SK, Yerramsetty S, Sahu N, K SB. Costunolide induces micronuclei formation, chromosomal aberrations, cytostasis, and mitochondrial-mediated apoptosis in Chinese hamster ovary cells. Cell Biol Toxicol 2018; 34: 125-142.

17. Tag HM, Khaled HE, Ismail HA, El-Shenawy NS. Evaluation of anti-inflammatory potential of the ethanolic extract of the Saussurea lappa root (costus) on adjuvant-induced monoarthritis in rats. J Basic Clin Physiol Pharmacol 2016; 27 : 71-78.

18. Chen Z, Zhang D, Li M, Wang B. Costunolide ameliorates lipoteichoic acid-induced acute lung injury via attenuating MAPK signaling pathway. Int Immunopharmacol 2018; 61: 283-289.

19. Chauhan RS, Bahuguna YM, Nautiyal MC, Cota-Sánchez JH. First account of vivipary in Saussurea lappa (Decne.) Sch. Bip. (Asteraceae). Braz J Bot 2018; 41: 507-514.

20. Abdel-Rahman M, Rezk MM, Ahmed-Farid OA, Essam S, Abdel Moneim AE. Saussurea lappa root extract ameliorates the hazards effect of thorium induced oxidative stress and neuroendocrine alterations in adult male rats. Environ Sci Pollut Res Int 2020; 27: 13237-13246.

21. Taylor PN, Albrecht D, Scholz A, Gutierrez-Buey G, Lazarus JH, Dayan CM, et al. Global epidemiology of hyperthyroidism and hypothyroidism. Nat Rev Endocrinol 2018; 14: 301-316.

22. Biondi B, Kahaly GJ, Robertson RP. Thyroid dysfunction and diabetes mellitus: two closely associated disorders. Endocr Rev 2019; 40: 789-824.

23. Chaker L, Bianco AC, Jonklaas J, Peeters RP. Hypothyroidism. The Lancet 2017; 390: 1550-1562.

24. Ross DS, Burch HB, Cooper DS, Greenlee MC, Laurberg P, Maia AL, et al. 2016 American Thyroid Association guidelines for diagnosis and management of hyperthyroidism and other causes of thyrotoxicosis. Thyroid 2016; 26: 1343-1421.

25. Diab N, Daya NR, Juraschek SP, Martin SS, McEvoy JW, Schultheiß UT, et al. Prevalence and Risk factors of thyroid Dysfunction in older Adults in the community. Sci Rep 2019; 9: 13156. 
26. Al Shahrani AS, El-Metwally A, Al-Surimi K, Salih SB, Saleh Y, Al-Shehri A, et al. The epidemiology of thyroid diseases in the Arab world: A systematic review. Journal of Public Health and Epidemiology Full Length Research Paper 2016; 8: 17-26.

27. Ali AAG, Altahir SA. Prevalence of thyroids dysfunction among Saudi adult males and females from (June-September 2016). Journal of Endocrinology and Diabetes 2016; 3: 1-3.

28. Aljabri KSJ, Alnasser MI, Facharatz, Bokhari SA, Alshareef MA, Khan PM, et al. The frequency of hypothyroidism in Saudi community-based hospital: A retrospective single centre study. Trends in Diabetes and Metabolism 2019; 1: doi 10.15761/ tdm.1000107.

29. Cappola AR, Desai AS, Medici M, Cooper LS, Egan D, Sopko G, et al. Thyroid and cardiovascular disease: research agenda for enhancing knowledge, prevention, and treatment. Circulation 2019; 139: 2892-2909.

30. Journy NM, Bernier MO, Doody MM, Alexander BH, Linet MS, Kitahara CM. Hyperthyroidism, hypothyroidism, and cause-specific mortality in a large cohort of women. Thyroid 2017; 27: 1001-1010.

31. Barrea L, Gallo M, Ruggeri RM, Giacinto PD, Sesti F, Prinzi N, et al. Nutritional status and follicular-derived thyroid cancer: an update. Crit Rev Food Sci Nutr 2020: 1-35.

32. Cho A, Chang Y, Ahn J, Shin H, Ryu S. Cigarette smoking and thyroid cancer risk: a cohort study. Br J Cancer 2018; 119: 638-645.

33. Riza E, Linos A, Petralias A, de Martinis L, Duntas L, Linos D. The effect of Greek herbal tea consumption on thyroid cancer: a case-control study. European Journal of Public Health 2015; 25: 1001-1005.

34. Sharma AK, Basu I, Singh S. Efficacy and safety of Ashwagandha root extract in subclinical hypothyroid patients: A double-blind, randomized placebo-controlled trial. The Journal of Alternative and Complementary Medicine 2018; 24: 243-248.

35. Trajč́́ková E, Kurin E, Slobodníková L, Straka M, Lichváriková A, Dokupilová S, et al. Antimicrobial and antioxidant properties of four Lycopus Taxa and an interaction study of their major compounds. Molecules 2020; 25: 1422.

36. Trifan A, Opitz SE, Josuran R, Grubelnik A, Esslinger N, Peter $S$, et al. Is comfrey root more than toxic pyrrolizidine alkaloids? Salvianolic acids among antioxidant polyphenols in comfrey (Symphytum officinale L.) roots. Food Chem Toxicol 2018; 112: 178-187.

37. Al-Snai AE. Chemical constituents and pharmacological effects of Lithospermum officinale. IOSR J Pharm 2019; 9: 12-21.

38. Onumah BM. Alternative and complementary treatment of thyroid disorders in thyroid cancer: A comprehensive guide to clinical management. Journal of Nuclear Medicine 2016; 58: 759.

39. Chuang TY, Lien CY, Hsu CH, Lu CW, Wu CH. Chinese herbal medicine alleviates thyroidectomy-induced cardiopulmonary exercise dysfunction in rats. Evid Based Complement Alternat Med 2020; 2020: 9415082.

40. Yang H, Cong Y, Wu T, Tang H, Ma M, Zeng J, et al. Clinical efficacy of Yingliu mixture combined with metimazole for treating diffuse goitre with hyperthyroidism and its impact on related cytokines. Pharmaceutical Biology 2017; 55: 258-263.

41. Shen HY, Li LZ, Xue KC, Hu DD, Gao YJ. Antitumor activity of fucoidan in anaplastic thyroid cancer via apoptosis and anti-angiogenesis. Molecular Medicine Reports 2017; 15: $2620-2624$.
42. Zhang Y, Li Y, Mao X, Yan C, Guo X, Guo Q, et al. Thyroid hormone synthesis: A potential target of a Chinese herbal formula Haizao Yuhu Decoction acting on iodine-deficient goiter. Oncotarget 2016; 7: 51699-51712.

43. Tousson E, El-Atrsh A, Mansour M, Abdallah A. Modulatory effects of Saussurea lappa root aqueous extract against ethephoninduced kidney toxicity in male rats. Environmental Toxicology 2019; 34: 1277-1284.

44. Abd Eldaim MA, Tousson E, El Sayed IET, Awd WM. Ameliorative effects of Saussurea lappa root aqueous extract against Ethephon-induced reproductive toxicity in male rats. Environmental Toxicology 2019; 34: 150-159.

45. Pyun H, Kang U, Seo EK, Lee K. Dehydrocostus lactone, a sesquiterpene from Saussurea lappa Clarke, suppresses allergic airway inflammation by binding to dimerized translationally controlled tumor protein. Phytomedicine 2018; 43: 46-54.

46. Choodej S, Pudhom K, Mitsunaga T. Inhibition of TNF- $\alpha$ -induced inflammation by Sesquiterpene Lactones from Saussurea lappa and semi-synthetic analogues. Planta Medica 2018; 84: 329-335.

47. Lin X, Peng Z, Fu X, Liu C, Xu Y, Ji W, et al. Volatile oil from Saussurea lappa exerts antitumor efficacy by inhibiting epithelial growth factor receptor tyrosine kinase-mediated signaling pathway in hepatocellular carcinoma. Oncotarget 2016; 7: 79761-79773.

48. Tejaswi JK, Rajan RG, Sara P. Biological evaluation of Saussurea lappa root extract for analgesic and anti-inflammatory activity. Asian Journal of Pharmaceutical Research and Development 2018; 6: 35-38.

49. Panthi S, Gao T. Diagnosis and management of primary hypothyroidism in traditional Chinese medicine (TCM) and traditional Indian medicine (Ayurveda). Int J Clin Endocrinol Metab 2015; 1: 009-012.

50. Cicatiello AG, Di Girolamo D, Dentice M. Metabolic effects of the intracellular regulation of thyroid hormone: old players, new concepts. Front Endocrinol (Lausanne) 2018; 9: 474.

51. Iglesias P, Bajo MA, Selgas R, Díez JJ. Thyroid dysfunction and kidney disease: an update. Reviews in Endocrine and Metabolic Disorders 2017; 18: 131-144.

52. Bolkiny Y, Tousson E, El-Atrsh A, Akela M, Farg E. Costus root extract alleviates blood biochemical derangements of experimentally-induced hypo- and hyperthyroidism in mice. Annual Research \& Review in Biology 2019; 31: 1-10.

53. Shrestha S, Bharti A, Rai R, Singh M. Assessment of Serum Minerals and Electrolytes in Thyroid Patients. International Journal of Advances in Scientific Research 2015; 1: 259.

54. Ahmed SB, Moghazy AM, Ahmed-Farid OA, Esebery HA. Effects of aqueous extract of polyherbal formulation against hyperthyroidism induced by L-thyroxin in a rat model. Biomedical Research and Therapy 2018; 5: 2876-2887.

55. Han J, Xian Z, Zhang Y, Liu J, Liang A. Systematic overview of Aristolochic acids: Nephrotoxicity, carcinogenicity, and underlying mechanisms. Front Pharmacol 2019; 10: 648.

56. Seca AML, Silva AMS, Pinto DCGA. Chapter 9 - Parthenolide and Parthenolide-like sesquiterpene lactones as multiple targets drugs: Current knowledge and new developments. Studies in Natural Products Chemistry 2017; 52: 337-372. 